\title{
Can those organic micro-pollutants that are recalcitrant in activated sludge treatment be removed from wastewater by biofilm reactors (slow sand filters)?
}

\author{
Mònica Escolà Casas, Kai Bester* \\ Environmental Science, Aarhus University, Frederiksborgvej 399, 4000 Roskilde, Denmark
}

\section{H I G H L I G H T S}

- A biofilm reactor (biofilter) can remove micro-pollutants from WWTP effluent.

- Sorption could be excluded as the dominant removal mechanism.

- Biodegradation was responsible for removing seven compounds.

- The removal efficiency was usually proportional to the hydraulic residencetime.

- Single first-order removal rates apply for most compounds
G R A P H I C A L A B S T R A C T

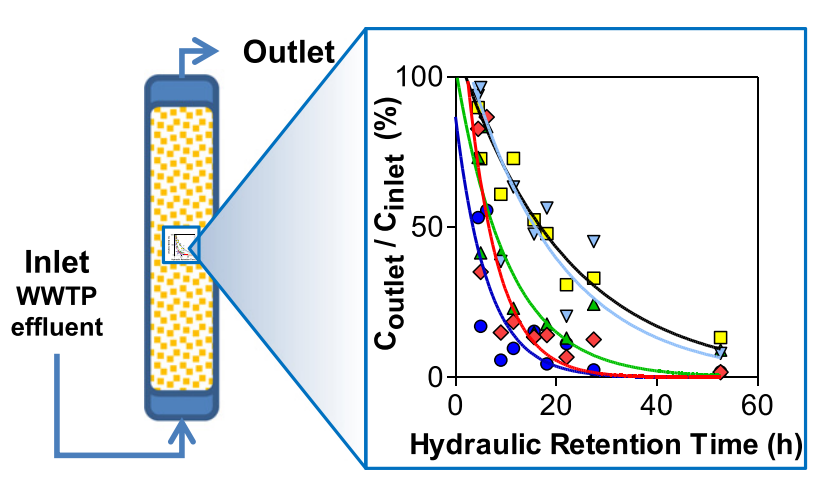

\section{A B S T R A C T}

The degradation of seven compounds which are usually recalcitrant in classical activated sludge treatment (e.g., diclofenac, propranolol, iopromide, iohexol, iomeprol tebuconazole and propiconazole) was studied in a biofilm reactor (slow sand filtration). This reactor was used to treat real effluent-wastewater at different flow rates (hydraulic loadings) under aerobic conditions so removal and degradation kinetics of these recalcitrant compounds were calculated. With the hydraulic loading rate of $0.012 \mathrm{~m}^{3} \mathrm{~m}^{2} \mathrm{~h}^{-1}$ the reactor removed 41,94 , 58,57 and $85 \%$ of diclofenac, propranolol, iopromide, iohexol and iomeprol respectively. For these compounds the removal efficiency was dependent on hydraulic residence-times. Only 59 and $21 \%$ of the incoming tebuconazole and propiconazole respectively were removed but their removal did not depend on hydraulic residence time. Biofilm reactors are thus efficient in removing micro-pollutants and could be considered as an option for advanced treatment in small wastewater treatment plants.

(c) 2014 Elsevier B.V. All rights reserved.

\footnotetext{
* Corresponding author. Tel.: +45 87158552 . E-mail address: kb@dmu.dk (K. Bester).
}

\section{Introduction}

A multitude of xenobiotics ( pharmaceuticals, biocides etc.) are present in current Wastewater Treatment Plant (WWTPs) effluents (Joss et al., 2006; Kormos et al., 2011; Ternes et al., 2007). Some exceed the environmental target concentrations (European Parliament, 2000, 
2013). To improve effluent quality, different processes such as activated carbon treatment, reverse osmosis and Advanced Oxidation Processes (AOPs) can be added to the conventional activated sludge treatment. Activated carbon and reverse osmosis are techniques that reach satisfactory removal rates but they are phase-transfer processes so they do not destroy the compounds in question (Choubert et al., 2011). On the other hand, AOPs can efficiently oxidize micro-pollutants, but they require intensive process control, have high operating costs and can produce by-products (Choubert et al., 2011; Lee et al., 2013; Prieto-Rodríguez et al., 2013; Reungoat et al., 2011, 2012; Stalter et al., 2010). Alternatively, biological processes such as biofilm reactors can also remove micro-pollutants (Bester and Schafer, 2009; Falås et al., 2012; Joss et al., 2008) and do not require as much process control as AOPs. Ideally, the microorganisms use the organic micro-pollutants to build up biomass or for gaining energy. Biofilm reactors can be implemented in biofilter systems (Banzhaf et al., 2012; Bester and Schafer, 2009; Bester et al., 2011; Janzen et al., 2009). Multiple studies focused on biofilm reactors for removing organic micro-pollutants from raw drinking water by using underground passage, bank filtration etc. which are somewhat similar, but usually not designed but grown in natural conditions (Andresen and Bester, 2006; Benner et al., 2013; Gray and Sedlak, 2005; Heberer et al., 2004; Laws et al., 2011; Scheytt et al., 2004, 2006; Ternes et al., 2007; Zearley and Summers, 2012).

Only a very limited amount of studies use porous media biofilm processes to remove organic micro-pollutants from wastewater (Bester and Schafer, 2009; Bester et al., 2011; Janzen et al., 2009; Matamoros et al., 2007, 2009; Reungoat et al., 2011).

It is known that the effectiveness of biofilm reactors depends on the hydraulic residence-time (HRT), the compound residence time and the biofilm surface area. Aerobic processes appeared to be the most efficient for the removal of many organic micro-pollutants, albeit a few compounds degrade better under anoxic conditions (Hijosa-Valsero et al., 2011; Matamoros et al., 2009; Rittmann, 1985). Apart from that, the most efficient configuration for the biodegradation of organic micropollutants is unknown and the mechanisms involved are unclear.

Usually there are two mechanisms relevant for porous media biofilm systems: biodegradation and sorption. Scheytt et al., 2004 demonstrated the influence of sorption even for a hydrophilic compound like diclofenac in a water-saturated sandy-sediment column in the laboratory. In that study, diclofenac was not biodegraded but sorbed to/retained by the soil. Thus it is important to discriminate the two processes: sorption and degradation.

This study focuses on the biodegradation of seven representative micro-pollutants that are commonly recalcitrant after activated sludge treatment: diclofenac, propranolol, iopromide, iohexol, iomeprol, propiconazole and tebuconazole (S1). Diclofenac and propranolol have been detected in WWTPs in the range 0.1-1 $\mu \mathrm{g} \mathrm{L}^{-1}$ (Scheurer et al., 2010; Thomas et al., 2007). Iopromide, iohexol and iomeprol are found in wastewater with concentrations of 1-100 $\mu \mathrm{g} \mathrm{L}^{-1}$ (Hirsch et al., 2000; Ternes and Hirsch, 2000). Propiconazole and tebuconazole are used as biocides present in wood and coatings, and therefore can be detected in WWTP in the range of 0.01-0.1 $\mu \mathrm{g} \mathrm{L} \mathrm{L}^{-1}$ (Bollmann et al., 2014; Kahle et al., 2008). All the selected compounds were present in the wastewater effluent used for the study, thus no additional spiking was conducted (Table 1 ).

This study aims to answer whether built porous media biofilm reactors can be considered as a solution to remove and degrade micro-pollutants in wastewater effluents from small WWTPs.

\section{Materials and methods}

\subsection{Biofilm reactor set-up}

The biofilm reactor was built using a glass column (500 mm length and $25 \mathrm{~mm}$ ID) from LCTech (Dorfen, Germany). The column was filled with quartz sand (50-70 mesh (i.e. 0.210-0.297 mm particle size)) from Sigma-Aldrich up to $29 \mathrm{~cm}$ (142 mL volume).

To achieve a faster establishment of biofilms, $3 \mathrm{~mL}$ of activated sludge (performing BOD removal as well as nitrification and denitrification) from Bjergmarken WWTP (Roskilde, Denmark) was placed at the start of the column. Fig. 1 shows the column set-up. Effluent wastewater saturated with oxygen from the same WWTP was pumped through the column using a Reglo-CPF digital pump from Ismatec (Wertheim, Germany). The water was pumped against gravity to facilitate the removal of air-bubbles and thus achieve a water-saturated flow, which allowed an easy control of hydraulics. To protect the pump from clogging, a glass-fiber filter (Grade GF/C: $1.2 \mu \mathrm{m}$ ) was installed at the inlet tube, to reject particles. The feed water tank was refrigerated to $4{ }^{\circ} \mathrm{C}$. Considering a maximum flow rate of $0.2 \mathrm{~mL} \mathrm{~min}^{-1}$, it is assumed that the feed warms up to room temperature $\left(20^{\circ} \mathrm{C}\right)$ in the feedline and in the pump, thus the reactor itself is at room temperature as well. This assumption has been verified in later experiments. The tubing and the biofilm reactor were covered with aluminum foil to prevent algae growth. The system was acclimatized and thus adapted to the respective water for three months and showed stable removal rates after that conditioning time.

\subsection{Materials}

Analytical standards of diclofenac, propranolol, iopromide, iohexol, iomeprol tebuconazole and propiconazole were obtained from Dr. Ehrensdorfer GmbH (Augsburg, Germany). Formic acid and gradient grade methanol were obtained from Merck (Darmstadt, Germany); water was from an in-house Millipore apparatus.

Table 1

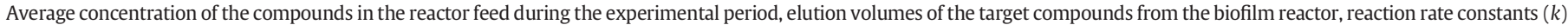
and percentage removal of the target compounds at minimum, intermediate and maximum flows.

\begin{tabular}{|c|c|c|c|c|c|c|}
\hline Target compound & $\begin{array}{l}\text { Feed concentration } \\
(\text { mean } \pm \mathrm{SD}) \\
(\mathrm{n}=18)\end{array}$ & Elution volume & $\begin{array}{l}\text { Reaction rate } \\
\text { constant }(k)\end{array}$ & $\begin{array}{l}\text { Removal } 1 \\
(\text { mean } \pm S D) \\
(\mathrm{n}=4) \\
\end{array}$ & $\begin{array}{l}\text { Removal } 2 \\
(\text { mean } \pm S D) \\
(n=5) \\
\end{array}$ & $\begin{array}{l}\text { Removal } 3 \\
(\text { mean } \pm S D) \\
(n=5)\end{array}$ \\
\hline \multirow[t]{2}{*}{$\overline{\text { Flow }\left[\mu \mathrm{L} \min ^{-1}\right]}$} & & & & 17 & 98 & 196 \\
\hline & {$\left[\mu \mathrm{g} \mathrm{L}^{-1}\right]$} & {$[\mathrm{mL}]$} & {$\left[\mathrm{h}^{-1}\right]$} & [\%] & [\%] & [\%] \\
\hline Propranolol & $0.055 \pm 0.015$ & 78.4 & 0.143 & $98 \pm 1$ & $94 \pm 2$ & $45 \pm 14$ \\
\hline Diclofenac & $0.24 \pm 0.047$ & 54 & 0.040 & $82 \pm 1$ & $41 \pm 2$ & 0 \\
\hline Propiconazole & $0.11 \pm 0.059$ & 62.4 & - & $21 \pm 22$ & $17 \pm 3$ & 0 \\
\hline Tebuconazole & $0.022 \pm 0.006$ & 65.6 & - & $59 \pm 20$ & $58 \pm 4$ & 0 \\
\hline Iohexol & $3.28 \pm 1.3$ & 53.2 & 0.101 & $91 \pm 8$ & $57 \pm 3$ & $25 \pm 18$ \\
\hline Iomeprol & $20.8 \pm 11$ & 53.2 & 0.090 & $93 \pm 10$ & $85 \pm 0.2$ & $17 \pm 12$ \\
\hline Iopromide & $2.9 \pm 0.83$ & 53.2 & 0.046 & $91 \pm 6$ & $58 \pm 0.3$ & 0 \\
\hline Tracer $(\mathrm{NaBr})$ & & 54.8 & & & & \\
\hline
\end{tabular}




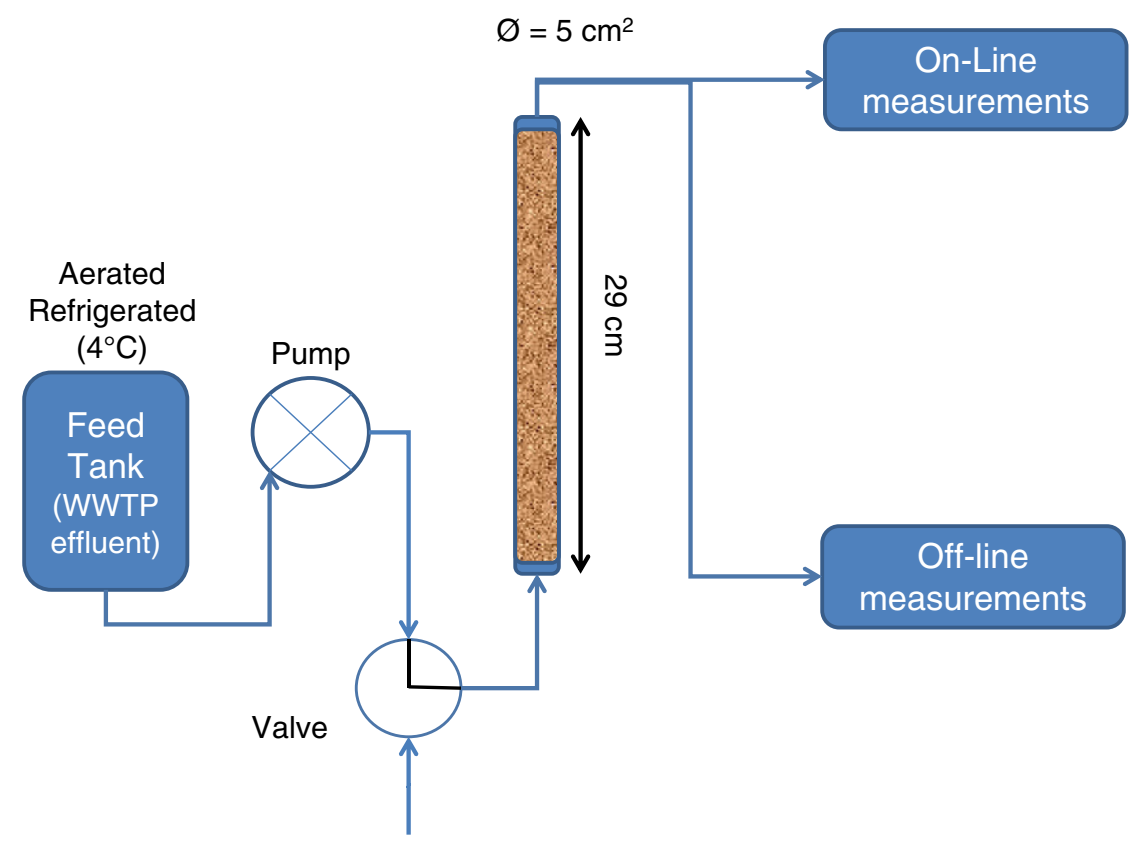

Fig. 1. Set-up of the reactor.

\subsection{Instruments}

High Performance Liquid Chromatography (HPLC) was used to monitor the target compounds. For this purpose, two different HPLC systems were used:

A) The process control HPLC-UV operated on-line in respect to the reactor column for the sorption/elution experiments. The apparatus consisted of a Dionex (DGP 3600SD pump, WPS3000TSL auto-sampler, TCC-3000SD solvent rack with a degasser and two six-port Valco-valves). The UV system was a DAD3000RS from Dionex.

B) The HPLC-MS/MS was used for quantifying the removal rates of organic micro-pollutants at environmental concentrations and operated independently (off-line) to the biofilm reactor column. The HPLC consisted of a Dionex DGP-3600 M pump, a WPS 3000 TSL autosampler and a column oven and degasser also from the Dionex 3000 series. The HPLC was operated with two ten-port Valco valves. The mass spectrometer was an API 4000 (ABSciex, Framingham, MA, USA). The API 4000 was operated in ESI in positive mode at $400{ }^{\circ} \mathrm{C}$ with a capillary voltage of $5500 \mathrm{~V}$. The instrumental details are given in the supplementary material (S2).

The samples for removal rates were taken in HPLC vials centrifuged for $5 \mathrm{~min}$ at $6000 \mathrm{rpm}$ (Z206A, Hemle, Wehingen, Germany) to remove particles. The supernatant was transferred to a new HPLC vial. $100 \mu \mathrm{L}$ of the aqueous samples were injected directly into the HPLC-MS/MS for quantification. In the HPLC-MS/MS a gradient elution consisting of methanol and Millipore water, both containing $0.2 \%$ formic acid ( $\mathrm{v} / \mathrm{v})$, on a Synergi-Polar column (Phenomenex, Torrance, California, USA) was used. More details are given in (S2-S3). A six point multilevel calibration was performed with two repeats each. As the samples were analyzed using $100 \mu \mathrm{L}$ injection of aqueous samples, the calibration ranges of the water samples corresponded to $0.01-0.5 \mu \mathrm{g} \mathrm{L}^{-1}$ (diclofenac, propranolol and tebuconazole), 0.1-0.6 $\mu \mathrm{g} \mathrm{\textrm {L } ^ { - 1 }}$ (propiconazole) and $0.5-25 \mu \mathrm{g} \mathrm{L} \mathrm{L}^{-1}$ (X-ray contrast media). The Limits of Quantification (LOQs) for each compound are documented in S2. Typically LOQs ranged from $0.01 \mu \mathrm{g} \mathrm{L}^{-1}$ (e.g. propranolol) to $0.64 \mu \mathrm{g} \mathrm{L}^{-1}$ (iohexol).

\subsection{Oxygen and total organic carbon (TOC) in the reactor column}

The oxygen was measured by a fiber optic oxygen sensor utilizing a Microx3 detector (PreSens, Regensburg, Germany). For the highest and lowest tested flow rates ( 200 and $25 \mu \mathrm{L} \mathrm{min}{ }^{-1}$ ) the oxygen in the water was measured with the oxygen micro-sensor in the inlet and outlet of the reactor column at room temperature.

The TOC samples were analyzed by a TOC 5000 analyzer (Shimazdu Kyoto, Japan). The measurements were calibrated using five potassium phthalate standard solutions with concentrations ranging from 2.5 to $50 \mathrm{mgC} \mathrm{L}^{-1}$. Samples and standard solutions were acidified to reach $0.05 \mathrm{M} \mathrm{HCl}(\mathrm{pH}<2)$. All the samples were analyzed within $24 \mathrm{~h}$ in respect to TOC.

\subsection{Feed water}

The feed water for the reactor was taken from Bjergmarken WWTP effluent. Over the experimental period the WWTP maintained a stable $\mathrm{pH}$ value of 8. The median values for Chemical Oxygen Demand (COD) and Biological Oxygen Demand (BOD) in the feed water were 29 and $2.8 \mathrm{mg} \mathrm{O}_{2} \mathrm{~L}^{-1}$ respectively. The full data can be seen in the supplementary material (S4). It was intended to work under as close as natural conditions, thus this water was not spiked but used as was. Besides BOD and particle removal, Bjergmarken operates nitrification, denitrification as well as phosphorus removal, thus the feed water for the biofilm reactor is not only poor on $\mathrm{BOD} / \mathrm{TOC}$ but also on $\mathrm{NH}_{4}^{+}, \mathrm{NO}_{2}^{-}$, $\mathrm{NO}_{3}^{-}$and phosphate.

2.6. Characterization of the reactor column: hydraulic retention times and compound specific retention times

To determine the porosity of the biofilm reactor and its hydraulic retention, a solution of sodium bromide (conservative tracer) was injected at a flow rate of $180 \mu \mathrm{L} \mathrm{min}^{-1}\left(21 \mathrm{~L} \mathrm{~m}^{-2} \mathrm{~h}^{-1}\right)$. This experiment was conducted with degassed tap water $(\mathrm{pH} 7)$ to allow direct detection by UV. $300 \mu \mathrm{L}$ of sodium bromide solution $\left(10 \mathrm{~g} \mathrm{~L}^{-1}\right)$ were injected into the flow with a syringe and an L-valve located directly after the pump (Fig. 1). The elution of the sodium bromide was monitored by 
transferring $100 \mu \mathrm{L}$ portions of the eluent of the biofilm reactor directly to the UV detector (set to $220 \mathrm{~nm}$ ) every $30 \mathrm{~min}$.

Using the same flow rate and water, the retention times of each of the compounds in the biofilm reactor were tested. Similar to the tracer experiment, $300 \mu \mathrm{L}$ multi-standard solution containing micropollutants with a concentration of $33 \mu \mathrm{g} \mathrm{mL}^{-1}$ (i.e. $11 \mu \mathrm{g}$ on column of each compound) was injected into the biofilm reactor column using the L-valve. The elution of the compounds from the biofilm reactor was monitored by transferring parts of the reactor effluent into the injection loop of the process control HPLC. This way, every $30 \mathrm{~min}$, $100 \mu \mathrm{L}$ of the flow passing the reactor were sent to the respective analytical column, using the Valco-valve of the HPLC-instrument. The compounds contained in this water sample were eluted from the analytical column using a gradient elution program and UV-detection. The gradient elution and the analytical columns are specified in the supplementary material (S5). Once the elution from the biofilm reactor was finished, a chromatogram for the reactor column was constructed from the single analytical runs, to identify the retention times of each compound in the reactor column.

\subsection{Removal of target compounds}

Inlet and outlet samples from the biofilm reactor were tested for ten different flow rates between 0.025 and $0.200 \mathrm{~mL} \mathrm{~min}{ }^{-1}$ which corresponded to HRTs ranging from 4 to $35 \mathrm{~h}$ respectively. The sampling period lasted one month and started six months after the column set-up was built. Every time the flow was changed, the reactor was given at least one residence time to stabilize before the samples were taken. For each tested flow a minimum of four replicates of $1 \mathrm{~mL}$ were taken (within the same sampling day).

The removal (\%R) was calculated comparing the outlet $\left(C_{\text {outlet }}\right)$ to the inlet $\left(C_{\text {inlet }}\right)$ concentrations of the reactor under continuous flow (Eq. (1)). Using the different HRTs as established by the different flow rates, kinetic data could be determined. From these, single first-order (SFO) kinetics reaction rate constants $k$ were calculated using Eq. (2)

$\% R=\left(1-\frac{C_{\text {outlet }}}{C_{\text {inlet }}}\right) * 100$

$\ln \left(\frac{C_{\text {outlet }}}{C_{\text {inlet }}}\right)=k * H R T$

$\mathrm{C}_{\text {outlet }}$ and $\mathrm{C}_{\text {inlet }}$ denote parent compound concentrations in the outlet and inlet of the biofilm reactor respectively and $k$ describes the parent compound removal rate constant (reaction rate constant). Ideally, a plot of $\ln \left(\mathrm{C}_{\text {outlet }} / \mathrm{C}_{\text {inlet }}\right)$ over HRT (determined at different flow rates) would give a linear correlation with a slope corresponding to $k$.

\section{Results}

\subsection{Hydraulic characterization of the reactor column}

The retention time of the sodium bromide (300 min) corresponded to a void volume (inner volume) of $53.9 \mathrm{~mL}$ (Fig. 2) and resulted in a porosity of 0.36 , which is typical for such materials (Schwarzenbach et al., 2003).

\subsection{Compound specific retention time (control experiment for degradation)}

The potential retention (sorption) to the reactor, was studied with typical concentrations of $550 \mu \mathrm{g} \mathrm{L}^{-1}$ of the respective micro-pollutants at the column effluent during the model experiment. The final results were achieved by comparing the reconstructed chromatograms obtained by the online HPLC-UV detection (Fig. 2, Table 1). As the peaks for sodium bromide, diclofenac, iohexol, iomeprol and iopromide coincide, these compounds are not sorbed at all (peak maximum for diclofenac is
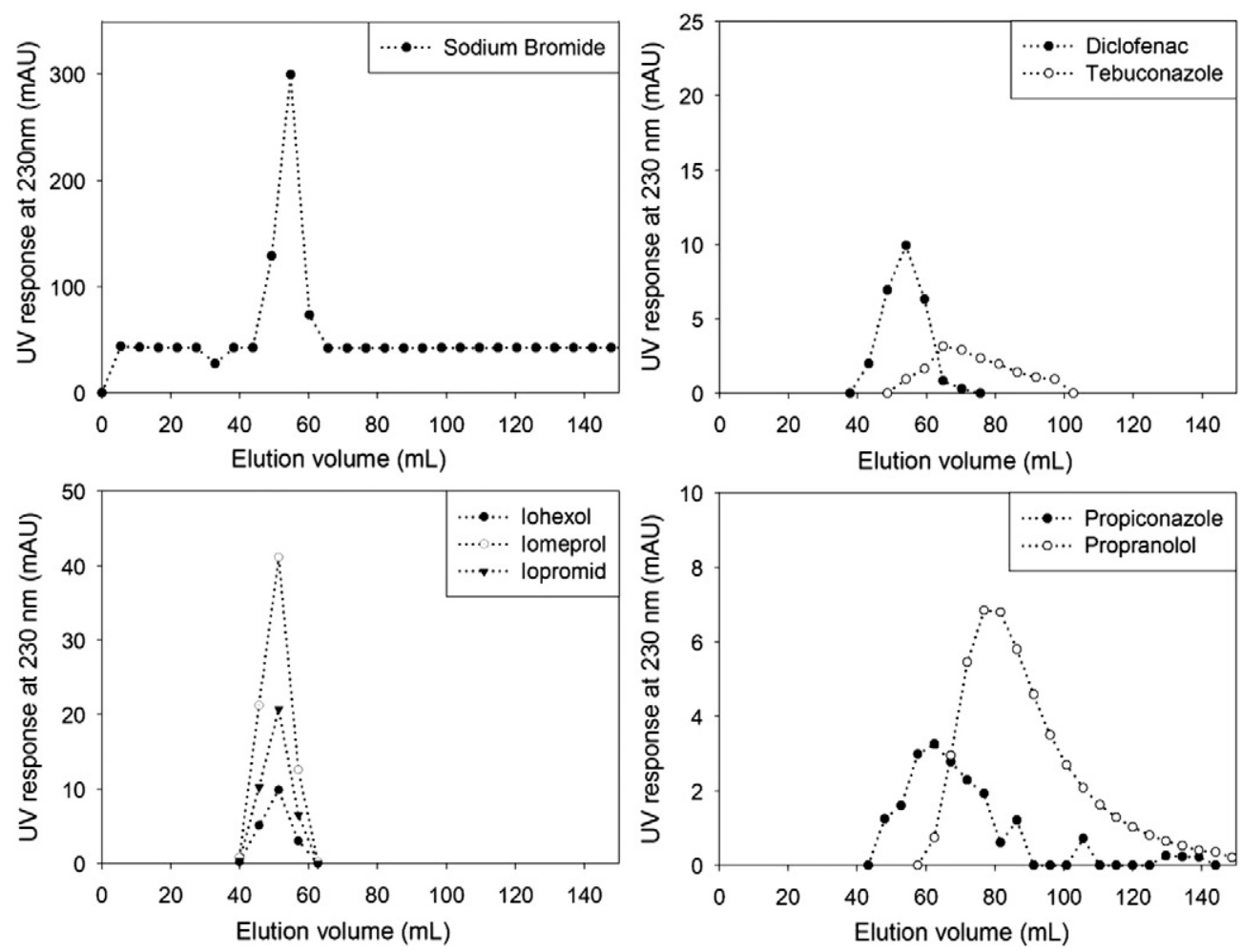

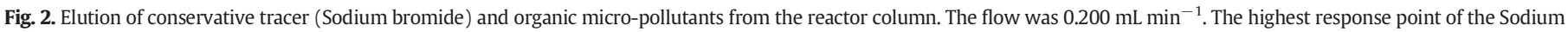
bromide (tracer) indicates the void-volume of the column. 
54 while the X-ray contrast media are eluted at $53.2 \mathrm{~mL}$ ). Tebuconazole, propiconazole and propranolol show slightly longer retention in the reactor (62-78 $\mathrm{mL}$ i.e., $1.38,1.34$ and 1.70 times the void volume). This finding agrees well with the known physico-chemical properties of the compounds (S1): diclofenac, iohexol, iomeprol and iopromide are hydrophilic compounds, while tebuconazole, propiconazole and propranolol have slightly elevated $\mathrm{K}_{\mathrm{ow}}$ 's. As the matrix of the reactor is quartz sand, the retention probably occurs to the biofilm in the system.

The low retention of these compounds combined with continuous load makes it very plausible that removal rates are due to biodegradation.

\subsection{Oxygen consumption and TOC}

The inlet water contained about $8 \mathrm{mg} \mathrm{O}_{2} \mathrm{~L}^{-1}$ (S6) and was thus practically oxygen saturated (Metcalf and Eddy, 2003). As oxygen was also present in the outlet of the reactor, the reactor was working fully under aerobic conditions. Oxygen decrease between inlet and outlet verified the presence of active microorganisms. For a flow rate of $25 \mu \mathrm{L} \mathrm{min}{ }^{-1}$ ( $35 \mathrm{~h}$ residence time) the oxygen concentration was decreased by $4.8 \mathrm{mg} \mathrm{L}^{-1}$. This compares to a measured decrease of $1.3 \mathrm{mg} \mathrm{TOC} \mathrm{L}^{-1}$. Theoretically this amount of oxygen should mineralize $1.8 \mathrm{mg} \mathrm{TOC} \mathrm{L}^{-1}$ but, as expected, the TOC in this experiment is only mineralized partially.

At a flow rate of $200 \mu \mathrm{L} \mathrm{min}^{-1}$ the concentration of oxygen was only decreased by $2.3 \mathrm{mg} \mathrm{O}_{2} \mathrm{~L}^{-1}$ (S6). This indicates that the activity of microorganisms was not limited by the oxygen but controlled by the carbon delivered by the hydraulic flow. For this flow the TOC in the inlet and outlet of the biofilter was not significantly different (S6).

\subsection{Concentrations, removal and reaction rate constants concerning organic micro-pollutants}

The concentrations of the organic micro-pollutants in the effluent wastewater which was used as feed water for the reactor varied slightly from batch to batch, depending on the respective collection week at the WWTP. In general, the two pharmaceuticals, propranolol and diclofenac, and the two fungicides, propiconazole and tebuconazole were present in concentrations in the order of $\mathrm{ng} \mathrm{L}^{-1}$ whereas the Xray contrast compounds occurred in the order of $\mu g \mathrm{~L}^{-1}$ (Table 1). Each batch was tested before starting an experiment. The reaction kinetics and removal rates were calculated with the actual concentrations during that experiment.

The removals were generally speaking high. Table 1 is showing the removals in percentage at three different flows tested in the reactor. As expected, the removal was dependent on the HRT, with the lowest removal at the lowest HRT.

For diclofenac proved to be difficult to remove. A quantitative removal of $82 \%$ was determined only at a flow rate of $17 \mu \mathrm{L} \mathrm{min}{ }^{-1}$ (Table 1). The same holds true for iopromide and iomeprol with removals up to 91 and $93 \%$. Diclofenac showed a good correlation between HRT and ln of outlet/inlet concentrations $\left(R^{2}=0.93\right)$ (Fig. 3). Iohexol was also removed quantitatively at high contact times (91\%) (Table 1$)$. The removal was so high, that only data-points up to 22.09 h HRT ( $86 \%$ removal) were thus used for calculating the reaction rate constant. Propranolol, was the easiest compound to degrade, reaching quantitative removal (94\%) already at a flow rate of $98 \mu \mathrm{L} \mathrm{min}^{-1}$ (Table 1 ), it thus appears to be the most reactive compound in this test. Finally, propiconazole and tebuconazole could only be removed to some extent ( 21 and 59\%).

For the degradation kinetics, experiments with different hydraulic retention times (different flow rates) were conducted. To assess the reaction kinetics the natural logarithm of $\left(\mathrm{C}_{\text {outlet }} / \mathrm{C}_{\text {inlet }}\right)$ was plotted in Fig. 3 in dependence of the hydraulic residence time (Eq. (2)). The hydraulic residence time is used as reaction time to calculate the reaction kinetics. The natural logarithm of $\left(\mathrm{C}_{\text {outlet }} / \mathrm{C}_{\text {inlet }}\right)$ was proportional to the reaction time for all compounds except for propiconazole and tebuconazole. Thus, it was possible to calculate reaction single first order rate constants ( $k$ in Eq. (2)). The effluents of experiments with the longest HRT resulted in very high removals and thus gave values close to LOQ's in some cases. Besides, for propranolol and iohexol the removal is almost complete, thus higher HRT points would not fit the regression. Such values were thus removed from the mathematical assessment (Fig. 3). The reaction rate constants ranged between $0.04 \mathrm{~h}^{-1}$ (diclofenac) and $0.143 \mathrm{~h}^{-1}$ (propranolol), mirroring thus the results from the removals. An overview on the reaction constants $(k)$ is given in Table 1.

\section{Discussion}

As diclofenac, iopromide, iohexol and iomeprol did not sorb to the material of the biofilter due to their high hydrophilicity (Fig. 2) the removal of these compounds was clearly attributed to biodegradation. This fact could actually be confirmed by clear reaction kinetics. Out of seven compounds, only propranolol, propiconazole and tebuconazole were slightly sorbed to the material with probably no consequences (no exchange of material necessary due to exhausted sorption capacity) for the operation of such a system in constant flow through mode, thus the removal of these compounds must also be attributed to biodegradation.

\subsection{Diclofenac}

The removal of diclofenac has been assessed before in other sand filter systems, so it was interesting to compare the obtained results with existing data. In this study, the removal rate of diclofenac was $41 \%$ in the biofilm reactor operating with an intermediate flow rate of $98 \mu \mathrm{L} \mathrm{min}{ }^{-1}$ (which corresponded to a hydraulic load of $0.012 \mathrm{~m}^{3} \mathrm{~m}^{-2} \mathrm{~h}^{-1}$ ). This value is similar to those reported from other slow sand filtration systems (hydraulic loading rates also in order of $\mathrm{L} \mathrm{m}^{-3} \mathrm{~h}^{-1}$ ) of Matamoros et al., 2009 and Scheytt et al., 2006 (Table 2). Two other studies, (Reungoat et al., 2011; Zearley and Summers, 2012) studied the removal of diclofenac in rapid sand filters (hydraulic loading rates in the order of $\mathrm{m}^{3} \mathrm{~m}^{-2} \mathrm{~h}^{-1}$ ) and obtained lower removal rates of $21 \pm 2.1 \%$ and $20 \pm 10 \%$ (Table 2). The reasons for the differences are probably the quite different retention times in the respective systems.

The reaction rate constant $(k)$ of $0.04 \mathrm{~h}^{-1}$ found in our study is similar to the one found by Matamoros et al., 2009, for a planted system operating on raw wastewater (Table 2) even though that one was operating on raw wastewater. Scheytt et al. (2006), found a diclofenac reaction rate constant of $0.37 \mathrm{~h}^{-1}$ (i.e 10 times higher than ours). On the other hand, Zearley and Summers (2012) found a diclofenac reaction rate constant in their drinking water system 50 times higher than the present study (Table 2). The different reaction rate constants in the different systems might be due to enhanced biomass (in those systems operating on raw wastewater) or more specialized biomass e.g., in the drinking water system. Other relevant differences include BOD loadings and different film surface areas per volume. At this moment it seems difficult to compare and systemize such results.

\subsection{Propranolol}

In this study, the degradation of propranolol has been assessed in a biofilm reactor for the first time. Thus the results can only be compared to different systems. Lin et al. (2010) conducted a sorptionbiodegradation study using river sediments and found that propranolol was strongly adsorbed to the soil whereas only little biodegradation was detected. Ribeiro et al. (2013) reported biodegradation of propranolol in incubated samples with activated sludge. The reaction rate constants $(k)$ were $0.096 \mathrm{~h}^{-1}$ and $0.113 \mathrm{~h}^{-1}$ for the $\mathrm{S}$ - and R-enantiomers of propranolol. On the other side, the present study showed that 

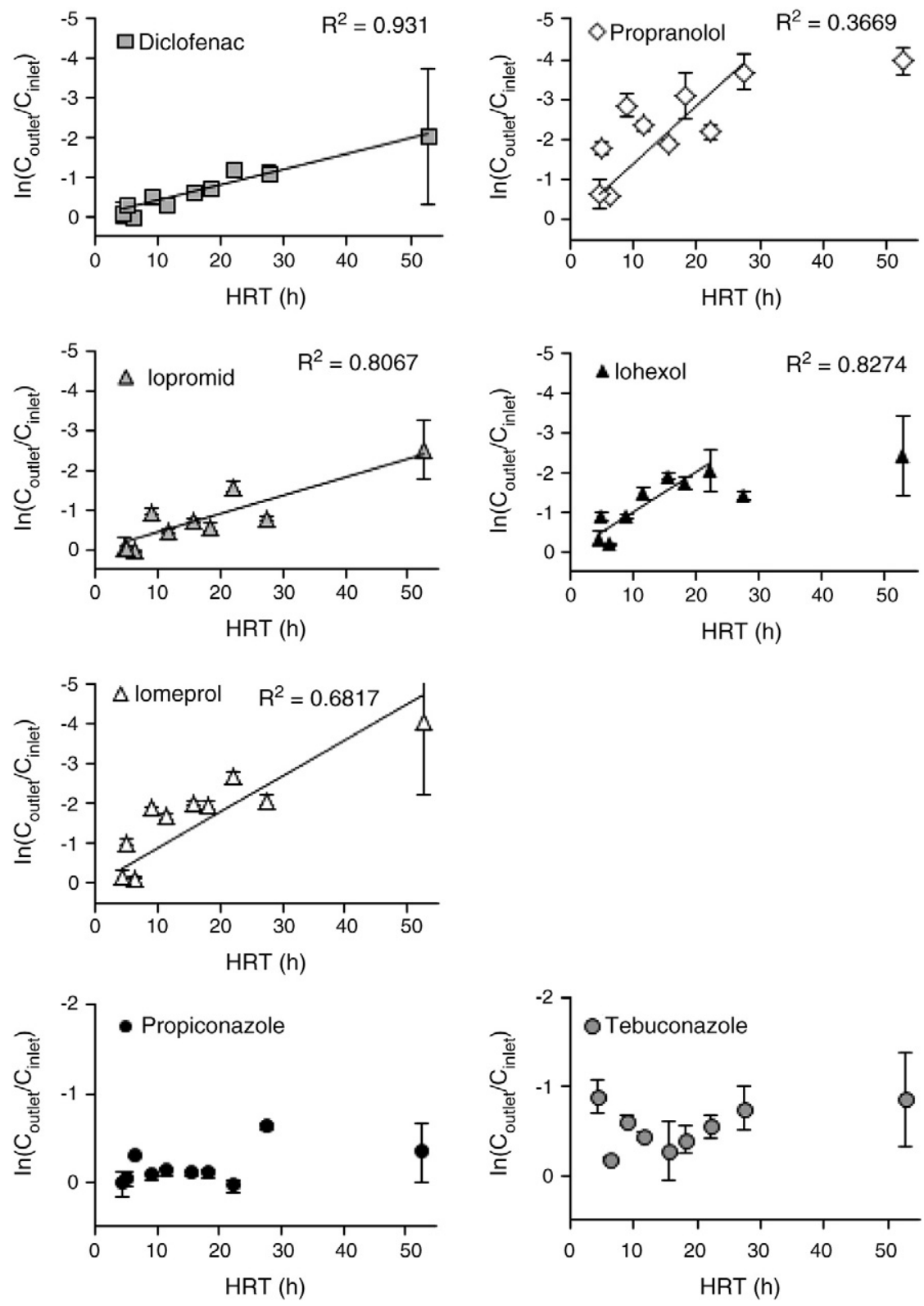

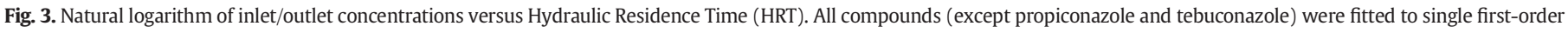
kinetics as expressed in Eq. (1). The reaction rate constants $(k)$ are presented in Table 2. Each datapoint is the average of 4 samples.

propranolol could be biodegraded with a rate constant of $0.143 \mathrm{~h}^{-1}$ (Table 1), which is a bit higher, but in the same order of magnitude as those found by Ribeiro et al. (2013). This would indicate that the removal of propranolol in an activated sludge tank of a similar size could have the same effectiveness but it would probably be more expensive to operate.

\subsection{Iopromide, iohexol and iomeprol}

In the present study it was found that X-ray contrast media iopromide, iohexol and iomeprol can be removed quantitatively by a low-flow passage through the biofilm reactor (Table 1, Fig. 3). The fact that biofilm reactors can degrade iodinated X-ray contrast media is also supported by a recent study on Moving Bed Biofilm Reactors (MBBRs) in which was shown that MBBRs can remove $79 \%$ and $73 \%$ of iohexol and diatrizoate respectively (Hapeshi et al., 2013). On the other hand, Zearley and Summers classified iopromide as recalcitrant for a quick sand reactor for drinking water treatment at a high hydraulic loading rate of $2.5 \mathrm{~m}^{3} \mathrm{~m}^{-2} \mathrm{~h}^{-2}$ (Zearley and Summers, 2012) (Table 2). These differences in the removals are in accordance with Benner et al. (2013) who, in their review, pointed out that longer retention times, as the slow-sand filtration, could enhance micro-pollutant removal.

In our study iohexol followed SFO only up to $22.9 \mathrm{~h}$, when it was almost completely removed. Similar removal and reaction rates were found for iomeprol. The reaction rate constant $(k)$ of iopromide however, is around two times lower than those of the other two X-ray contrast media (Table 1). This is in the same line than a previous study that described common degradation pathways and biodegradation rates of iohexol and iomeprol in aerobic soils (Kormos et al., 2010).

\subsection{Propiconazole and tebuconazole}

Propiconazole and tebuconazole are compounds with very similar chemical structures, which might explain, why they behave in a similar way concerning the retention in the biofilter and kinetics (see Figs. 2 and 3). In addition, for the first time, it was shown that these fungicides 
Table 2

Comparison of operation conditions as well as removals and reaction rate constants of the current study with other similar studies.

\begin{tabular}{|c|c|c|c|c|c|}
\hline Parameter & Present study & Zearley and Summers, 2012 & Reungoat et al., 2011 & Scheytt et al., 2006 & Matamoros et al., 2007 \\
\hline Water type & Real wastewater effluent & $\begin{array}{l}\text { River water impacted by } \\
\text { anthropogenic sources }\end{array}$ & $\begin{array}{l}\text { Pre-treated wastewater } \\
\text { effluent }\end{array}$ & Synthetic wastewater & Raw wastewater \\
\hline Classification & Slow sand filtration & Rapid sand filtration & Rapid sand filtration & Slow sand filtration & Slow sand filtration \\
\hline $\begin{array}{l}\text { Hydraulic loading rate } \\
\qquad\left[\mathrm{m}^{3} \mathrm{~m}^{-2} \mathrm{~h}^{-1}\right]\end{array}$ & 0.012 & 2.5 & 6 & 0.00917 & 0.0029 \\
\hline Filter (particle size) [mm] & $\begin{array}{l}\text { Quartz sand } \\
(0.21-0.29)\end{array}$ & Sand $(0.45)$ & Sand (2.25) & $\begin{array}{l}\text { Sandy sediment } \\
(0.063-0.630) \\
\left(\mathrm{f}_{\mathrm{oc}}=0.13 \%\right)\end{array}$ & $\begin{array}{l}\text { Coarse gravel } \\
(8-16) \\
\text { Gravel } \\
(0-4)\end{array}$ \\
\hline Initial TOC/DOC $\left[\mathrm{mg} \mathrm{C} \mathrm{L}^{-1}\right]$ & 4.86 and 7.58 & $3.1 \pm 0.3(\mathrm{TOC})$ & $11.2 \pm 0.4(\mathrm{DOC})$ & Not tested & Not tested \\
\hline HRT & $9.01 \mathrm{~h}$ & $7.9 \mathrm{~min}$ & $2 \mathrm{~h}$ & $\begin{array}{l}0.108 \mathrm{~h} \\
\text { (unsaturated) }\end{array}$ & 342 \\
\hline TOC/DOC removal & Not tested & $7.2 \pm 2.8 \%(\mathrm{TOC})$ & $22 \pm 3 \%(\mathrm{DOC})$ & Not tested & Not tested \\
\hline $\begin{array}{l}\text { Diclofenac initial concentration } \\
{\left[\mu \mathrm{g} \mathrm{L}^{-1}\right]}\end{array}$ & $0.242 \pm 0.047$ & $0.252 \pm 0.090$ & Not specified & 1 (spiked) & $0.82(0.48-1.28)$ \\
\hline Diclofenac removal [\%] & $41.7 \pm 2$ & $21 \pm 2.1$ & $\begin{array}{l}20 \pm 10 \\
\text { (from graph) }\end{array}$ & 35 & $39 \pm 22$ \\
\hline $\begin{array}{l}\text { Diclofenac reaction rate constant }(k) \\
{\left[\mathrm{h}^{-1}\right]}\end{array}$ & 0.040 & 1.92 & Not tested & 0.37 & $0.004^{\mathrm{a}}$ \\
\hline Iopromide removal [\%] & $58.8 \pm 3$ & $13 \pm 18$ & Not tested & Not tested & Not tested \\
\hline $\begin{array}{l}\text { Iopromide reaction rate constant }(k) \\
{\left[\mathrm{h}^{-1}\right]}\end{array}$ & 0.046 & 1.26 & Not tested & Not tested & Not tested \\
\hline
\end{tabular}

a Calculated from $\mathrm{K}_{\mathrm{A}}$ value.

can also be removed to some extent by biofilm reactors. No correlation between HRT and removal (Fig. 3) was observed. Eventually this could mean that only one of the respective stereoisomers is degraded in this reactor. Propiconazole has two chiral centers while tebuconazole has one, resulting in four stereoisomers for propiconazole and two for tebuconazole.

\subsection{Overall discussions}

Such biofilm reactors are able to remove compounds that AOPs, especially ozonation as performed in full-scale, cannot remove easily. Though, most probably, the biodegradation described in this paper for the targeted compounds does not lead to their mineralization. Whether or not biofilm reactors are thus producing less transformation products from the organic micro-pollutants than AOPs will be an interesting topic for future studies.

It is important to remark, that the built porous media biofilm reactor was operated for over 10 months without signs of clogging. Besides, the reactor was easy to control in terms of hydraulics and sorption of micropollutants. This is an advantage over soil systems, which are heterogeneous in their composition and therefore difficult to control.

The major disadvantage of biofilm reactors as slow sand filtration is the low-operating hydraulic loading rates. Considering a flow rate of $100 \mu \mathrm{L} / \mathrm{min}$ in our system and a loading rate of $0.293 \mathrm{~m}^{3} \mathrm{~m}^{-2} \mathrm{~d}^{-1} \mathrm{a}$ treatment plant operating $120.000 \mathrm{~m}^{3} \mathrm{~d}^{-1}$ equaling 600.000 persons would need an area of $0.41 \mathrm{~km}^{2}$, which is about the same size as bank filtration systems with underground passage. While this is a bit prohibitive at this size, a small plant operating for 50.000 persons would need $20.000 \mathrm{~m}^{2}$.

\section{Conclusions}

Porous media biofilm reactors can be constructed and used for removal of organic micro-pollutants from current wastewater effluents. Compounds that are recalcitrant to activated sludge and AOPs such as iodinated X-ray contrast media, diclofenac and propranolol can be removed by low-flow operation in porous media biofilm reactors. Therefore porous media biofilm reactors (slow sand filters) could be a cheap and easy way to polish effluents from activated sludge reactors of small WWTP in respect of removal of organic micro-pollutants.

\section{Acknowledgments}

The authors want to acknowledge the AUFF grant: Advanced water purification using bio-inorganic nanocatalysts and soil filters. The authors are indebted to the personnel of WWTP Bjergmarken that was always helpful considering provisions of samples and data on their WWTP. Aasbjørn Haaning Nielsen and Jes Vollertsen of Aalborg University helped with setting up the oxygen sensing.

\section{Appendix A. Supplementary data}

Supplementary data to this article can be found online at http://dx. doi.org/10.1016/j.scitotenv.2014.10.113.

\section{References}

Andresen J, Bester K. Elimination of organophosphate ester flame retardants and plasticizers in drinking water purification. Water Res 2006;40(3):621-9.

Banzhaf S, Nödler K, Licha T, Krein A, Scheytt T. Redox-sensitivity and mobility of selected pharmaceutical compounds in a low flow column experiment. Sci Total Environ 2012;438:113-21.

Benner J, Helbling DE, Kohler H-PE, Wittebol J, Kaiser E, Prasse C, Ternes TA, Albers CN, Aamand J, Horemans B, Springael D, Walravens E, Boon N. Is biological treatment a viable alternative for micropollutant removal in drinking water treatment processes? Water Res 2013;47:5955-76.

Bester K, Schafer D. Activated soil filters (bio filters) for the elimination of xenobiotics (micro-pollutants) from storm- and wastewaters. Water Res 2009;43(10):2639-46.

Bester K, Banzhaf S, Burkhardt M, Janzen N, Niederstrasser B, Scheytt T. Activated soil filters for removal of biocides from contaminated run-off and waste-waters. Chemosphere 2011;85(8):1233-40.

Bollmann UE, Tang C, Eriksson E, Jonsson K, Vollertsen J, Bester K. Biocides in urban wastewater treatment plant influent at dry and wet weather: concentrations, mass flows and possible sources. Water Res 2014;60:64-74.

Choubert JM, Martin Ruel S, Esperanza M, Budzinski H, Miege C, Lagarrigue C, Coquery M. Limiting the emissions of micro-pollutants: what efficiency can we expect from wastewater treatment plants? Water Sci Technol 2011;63(1):57-65.

European Parliament C. Directive 2000/60/EC of the European Parliament and of the Council of 23 October 2000 establishing a framework for Community action in the field of water policy. Official Journal L, 327; 2000. p. 1-73.

European Parliament C. Directive 2013/39/EU of the European Parliament and of the Council of 12 August 2013 amending Directives 2000/60/EC and 2008/105/EC as regards priority substances in the field of water policy. Official Journal L, 226; 2013. p. 000-0017.

Falås P, Baillon-Dhumez A, Andersen HR, Ledin A, la Cour Jansen J. Suspended biofilm carrier and activated sludge removal of acidic pharmaceuticals. Water Res 2012; 46(4):1167-75.

Gray JL, Sedlak DL. The fate of estrogenic hormones in an engineered treatment wetland with dense macrophytes. Water Environ Res 2005;77(1):24-31. 
Hapeshi E, Lambrianides A, Koutsoftas P, Kastanos E, Michael C, Fatta-Kassinos D. Investigating the fate of iodinated X-ray contrast media iohexol and diatrizoate during microbial degradation in an MBBR system treating urban wastewater. Environmental Science and Pollution Research International; 2013.

Heberer T, Mechlinski A, Fanck B, Knappe A, Massmann G, Pekdeger A, Fritz B. Field studies on the fate and transport of pharmaceutical residues in bank filtration. Ground Water Monit Remediat 2004;24(2):70-7.

Hijosa-Valsero M, Matamoros V, Sidrach-Cardona R, Pedescoll A, Martin-Villacorta J, Garcia J, Bayona JM, Becares E. Influence of design, physico-chemical and environmental parameters on pharmaceuticals and fragrances removal by constructed wetlands. Water Sci Technol 2011;63(11):2527-34.

Hirsch R, Ternes TA, Lindart A, Haberer K, Wilken RD. A sensitive method for the determination of iodine containing diagnostic agents in aqueous matrices using LCelectrospray-tandem-MS detection. Fresenius J Anal Chem 2000;366(8):835-41.

Janzen N, Banzhaf S, Scheytt T, Bester K. Vertical flow soil filter for the elimination of micro pollutants from storm and wastewater. Chemosphere 2009;77(10):1358-65.

Joss A, Zabczynski S, Gobel A, Hoffmann B, Loffler D, McArdell CS, Ternes TA, Thomsen A, Siegrist H. Biological degradation of pharmaceuticals in municipal wastewater treatment: proposing a classification scheme. Water Res 2006;40(8):1686-96.

Joss A, Siegrist H, Ternes TA. Are we about to upgrade wastewater treatment for removing organic micro-pollutants? Water Sci Technol 2008;57(2):251-5.

Kahle M, Buerge IJ, Hauser A, Muller MD, Poiger T. Azole fungicides: occurrence and fate in wastewater and surface waters. Environ Sci Technol 2008;42(19):7193-200.

Kormos JL, Schulz M, Kohler H-PE, Ternes TA. Biotransformation of selected iodinated $\mathrm{X}$-ray contrast media and characterization of microbial transformation pathways. Environ Sci Technol 2010;44(13):4998-5007.

Kormos JL, Schulz M, Ternes TA. Occurrence of iodinated X-ray contrast media and their biotransformation products in the urban water cycle. Environ Sci Technol 2011; 45(20):8723-32.

Laws BV, Dickenson ERV, Johnson TA, Snyder SA, Drewes JE. Attenuation of contaminants of emerging concern during surface-spreading aquifer recharge. Sci Total Environ 2011;409(6):1087-94.

Lee Y, Gerrity D, Lee M, Bogeat AE, Salhi E, Gamage S, Trenholm RA, Wert EC, Snyder SA, von Gunten U. Prediction of micropollutant elimination during ozonation of municipal wastewater effluents: use of kinetic and water specific information. Environ Sci Technol 2013:47(11):5872-81.

Lin AY-C, Lin C-A, Tung H-H, Chary NS. Potential for biodegradation and sorption of acetaminophen, caffeine, propranolol and acebutolol in lab-scale aqueous environments. J Hazard Mater 2010;183(1-3):242-50.

Matamoros V, Arias C, Brix H, Bayona JM. Removal of pharmaceuticals and personal care products (PPCPs) from urban wastewater in a pilot vertical flow constructed wetland and a sand filter. Environ Sci Technol 2007;41(23):8171-7.
Matamoros V, Arias C, Brix H, Bayona JM. Preliminary screening of small-scale domestic wastewater treatment systems for removal of pharmaceutical and personal care products. Water Res 2009;43:55-62.

Metcalf, Eddy I. Wastewater Engineering: Treatment and Reuse. McGraw-Hill; 2003.

Prieto-Rodríguez L, Oller I, Klamerth N, Agüera A, Rodríguez EM, Malato S. Application of solar AOPs and ozonation for elimination of micro-pollutants in municipal wastewater treatment plant effluents. Water Res 2013;47(4):1521-8.

Reungoat J, Escher BI, Macova M, Keller J. Biofiltration of wastewater treatment plant effluent: effective removal of pharmaceuticals and personal care products and reduction of toxicity. Water Res 2011;45(9):2751-62.

Reungoat J, Escher BI, Macova M, Argaud FX, Gernjak W, Keller J. Ozonation and biological activated carbon filtration of wastewater treatment plant effluents. Water Res 2012; 46:863-72.

Ribeiro AR, Afonso CM, Castro PML, Tiritan ME. Enantioselective biodegradation of pharmaceuticals, alprenolol and propranolol, by an activated sludge inoculum. Ecotoxicol Environ Saf 2013;87:108-14

Rittmann BE. Biological processes and organic micro-pollutants in treatment processes. Sci Total Environ 1985;47:99-113.

Scheurer M, Ramil M, Metcalfe CD, Groh S, Ternes TA. The challenge of analyzing betablocker drugs in sludge and wastewater. Anal Bioanal Chem 2010;396(2):845-56.

Scheytt T, Mersmann P, Leidig M, Pekdeger A, Heberer T. Transport of pharmaceutically active compounds in saturated laboratory columns. Ground Water 2004;42(5): 767-73.

Scheytt TJ, Mersmann P, Heberer T. Mobility of pharmaceuticals carbamazepine, diclofenac, ibuprofen, and propyphenazone in miscible-displacement experiments. J Contam Hydrol 2006;83(1-2):53-69.

Schwarzenbach R, Gschwend P, Imboden D. Environmental Organic Chemistry. WileyInterscience; 2003.

Stalter D, Magdeburg A, Weil M, Knacker T, Oehlmann J. Toxication or detoxication? In vivo toxicity assessment of ozonation as advanced wastewater treatment with the rainbow trout. Water Res 2010;44(2):439-48.

Ternes TA, Hirsch R. Occurrence and behavior of X-ray contrast media in sewage facilities and the aquatic environment. Environ Sci Technol 2000;34(13):2741-8.

Ternes TA, Bonerz M, Herrmann N, Teiser B, Andersen HR. Irrigation of treated wastewater in Braunschweig, Germany: an option to remove pharmaceuticals and musk fragrances. Chemosphere 2007;66(5):894-904.

Thomas KV, Dye C, Schlabach M, Langford KH. Source to sink tracking of selected human pharmaceuticals from two Oslo city hospitals and a wastewater treatment works. J Environ Monit 2007;9(12):1410-8.

Zearley TL, Summers RS. Removal of trace organic micro-pollutants by drinking water biological filters. Environ Sci Technol 2012;46(17):9412-9. 